\title{
Methyl Jasmonate Promotes Apple Fruit Degreening Independently of Ethylene Action
}

\author{
Xuetong Fan and James P. Mattheis \\ U.S. Department of Agriculture, Agricultural Research Service, Tree Fruit \\ Research Laboratory, 1104 North Western Avenue, Wenatchee WA 98801
}

Additional index words. color, Malus $\times$ domestica, MCP, respiration

\begin{abstract}
Climacteric 'Fuji' apples (Malus $\times$ domestica Borkh.) were treated with water, $0.45 \mathrm{mmol} \cdot \mathrm{m}^{-3} 1$-methylcyclopropene $(\mathrm{MCP}), 2 \mathrm{mmol} \cdot \mathrm{L}^{-1}$ methyl jasmonate $(\mathrm{MJ})$, or both MCP and MJ. Fruit were kept at $20^{\circ} \mathrm{C}$ for 17 days after treatment. Ethylene production, respiration, and color change were all inhibited following MCP treatment. Ethylene production following MJ treatment fluctuated below and above that of controls, but was representative of postclimacteric apples at all times. Rates of respiration and color change were enhanced by MJ, even when fruit were previously treated with MCP. The results indicate that $\mathrm{MJ}$ can enhance rate of color change and respiration in apple fruit independently of ethylene action.
\end{abstract}

Jasmonates [jasmonic acid and its methyl ester, methyl jasmonate (MJ)] are cyclopentanone compounds that modulate a wide range of plant responses (Creelman and Mullet 1997; Sembdner and Parthier, 1993), including promotion of chlorophyll degradation (Abeles et al., 1989; Hung and Kao, 1996; Ueda and Kato, 1980). Exogenous MJ promotes chlorophyll degradation and $\beta$-carotene accumulation in tomato (Saniewski and Czapski, 1983) and chlorophyll degradation in apple fruit (Perez et al., 1993). Jasmonates also stimulate ethylene biosynthesis, and the endogenous jasmonate concentration rises coincident with the onset of ripening in apple and tomato fruit (Fan et al., 1998b). Exogenous jasmonates accelerate degreening and stimulate ethylene production in apple fruit in a concentration- and developmental stagedependent manner (Fan et al., 1997, 1998c). Methyl jasmonate is more effective in stimulating degreening than is ethephon (an ethylene releasing agent) on a molar basis. However, it is unclear whether the effect of $\mathrm{MJ}$ on degreening is related to its effect on ethylene action. The ethylene action inhibitor MCP (Sisler and Serek, 1997) delays senescence of cut flowers and potted plants at very low concentrations (Serek et al., 1994; Sisler et al.,

\footnotetext{
Received for publication 16 Apr. 1998. Accepted for publication 11 Sept. 1998. We thank BioTechnology for Horticulture for providing 1-methylcyclopropene (MCP), and David Buchanan and Janie Gausman for technical assistance. Mention of a trade mark, proprietary product, or vendor does not constitute a guarantee or warranty of the product by the U.S. Dept. of Agriculture and does not imply its approval to the exclusion of other products or vendors that also may be suitable. The cost of publishing this paper was defrayed in part by the payment of page charges. Under postal regulations, this paper therefore must be hereby marked advertisement solely to indicate this fact.
}

1996). In this study, MCP was used to investigate whether enhanced degreening of apple fruit by $\mathrm{MJ}$ requires ethylene action.

\section{Materials and Methods}

Climacteric 'Fuji' apples with a mean internal ethylene concentration of $32.5 \mu \mathrm{L} \cdot \mathrm{L}^{-3}$ (range 10.1-67.9) were harvested from a commercial orchard near Orondo, Wash. Fruit were treated with water (control), $2.0 \mathrm{mmol} \cdot \mathrm{L}^{-1}$ MJ (Bedoukian Research, Danbury, Conn.), $0.45 \mathrm{mmol} \cdot \mathrm{m}^{-3} \mathrm{MCP}$ (BioTechnology for Horticulture Inc., Burr Ridge, Ill.), or a combination of the two chemicals. There were four replicates of five apples each per treatment. Methyl jasmonate was applied in water as described by Fan et al. (1998c). For MCP treatment, each replicate group of apples was placed in a 20-L glass jar and MCP was injected into the jar through a rubber septum in the lid. After $12 \mathrm{~h}$, fruit were removed from the jar and dipped in water for $2 \mathrm{~min}$. For the combination $\mathrm{MCP}+\mathrm{MJ}$ treatment, fruit were dipped in $2 \mathrm{mmol} \cdot \mathrm{L}^{-1} \mathrm{MJ}$ for $2 \mathrm{~min}$ after the MCP treatment. All fruit were enclosed in 20$\mathrm{L}$ jars for $12 \mathrm{~h}$ and dipped in $0.02 \%$ Tween 20 $(\mathrm{v} / \mathrm{v})$ and $1 \%(\mathrm{v} / \mathrm{v})$ ethanol whether or not MJ or MCP was present. After treatment, fruit were kept at $20^{\circ} \mathrm{C}$, and ethylene production, respiration, and color were measured $0,1,2,3$, $5,7,9,11,13,15$, and $17 \mathrm{~d}$ after treatment. Measurement of fruit color, internal ethylene concentration, ethylene production, and respiration rates were as described previously (Fan et al., 1998c). The nonblushed area of each individual fruit was marked, and color on the same spot was recorded as CIE L*, a*, b* with a chromameter (model CR-200; Minolta, Japan) using CIE illuminant $\mathrm{C}$ and an $8-\mathrm{mm}$ measuring aperture. The chromameter was calibrated with a standard white plate (CRA43) and $d / 0$ was the illuminant/viewing geometry. Hue and chroma values were calculated from $\mathrm{a}^{*}$ and $\mathrm{b}^{*}$ (McGuire, 1992).
Ethylene production was reduced by MJ 2, 3 , and $5 \mathrm{~d}$ after treatment (Fig. 1A) but remained at a rate indicative of postclimacteric apple fruit (Burg and Burg, 1962). Ethylene production recovered $7 \mathrm{~d}$ after treatment, and was higher than the controls thereafter. There was no detectable ethylene production by MCPtreated fruit throughout the 17-d period, suggesting that continued ethylene biosynthesis by apple fruit requires continuous ethylene action. Another ethylene action inhibitor, diazocyclopentadiene (DACP), also inhibits ethylene production in postclimacteric apple fruit, but the inhibition is only $\approx 50 \%$ and lasts $<13 \mathrm{~d}$ at $20^{\circ} \mathrm{C}$, even at a concentration of 83 $\mathrm{mmol} \cdot \mathrm{m}^{-3}$ (Fan et al., 1998a). Blankenship and Sisler (1993) reported that DACP at the same concentration inhibited ethylene production for at least $20 \mathrm{~d}$ at $21^{\circ} \mathrm{C}$.

Treatment with MJ overcame some of the inhibition of ethylene production by MCP, but not until $9 \mathrm{~d}$ after treatment. Responses elicited by exogenous MJ are dependent on the fruit's stage of development (Fan et al., 1998b, 1998c; Saniewski et al., 1987). Exogenous jasmonate stimulates ethylene production in preclimacteric fruit but inhibits it in postclimacteric fruit. Ethylene production was not detectable following MCP treatment of climacteric fruit in this study. Renewed ethylene production $9 \mathrm{~d}$ after $\mathrm{MJ}$ treatment of $\mathrm{MCP}$ treated fruit was similar to that following MJ treatment of preclimacteric fruit (Fan et al., 1997). 1-Methylcyclopropene presumably binds to ethylene receptor(s) and blocks ethylene action (Sisler and Serek, 1997), but the mechanism of action of MJ is not known.

Treatment with MJ stimulated respiration (Fig. 1B), while treatment with MCP inhibited it. The respiration rate of MCP-treated fruit was $\approx 50 \%$ that of controls, suggesting that climacteric respiration requires continuous ethylene action. Ethylene stimulates respiration in almost all fruit tested (Abeles et al., 1992). Although MJ promoted respiration, it inhibited ethylene production immediately after treatment. Furthermore, MJ promoted respiration even when ethylene action was blocked by MCP. This effect does not appear to involve ethylene action, and MJ and MCP appear to have opposing effects on apple fruit respiration.

Treatment with MJ hastened the decrease in hue and the increase in chroma relative to controls (Fig. 2). By definition, chroma indicates the degree of departure from gray toward a pure chromatic color, and hue is the visually perceived color (McGuire, 1992). In this study, the decline in hue angle indicated the change from green to yellow, and the increase in chroma reflected increasing intensity of yellow color. Both chroma and hue values increased following $\mathrm{MJ}$ treatment, a change indicative of the development of the deep yellow ground color that develops as 'Fuji' apples ripen. In contrast, MCP treatment inhibited color change, suggesting that the change that occurs during normal apple fruit ripening requires ethylene action. Exogenous MJ pro- 


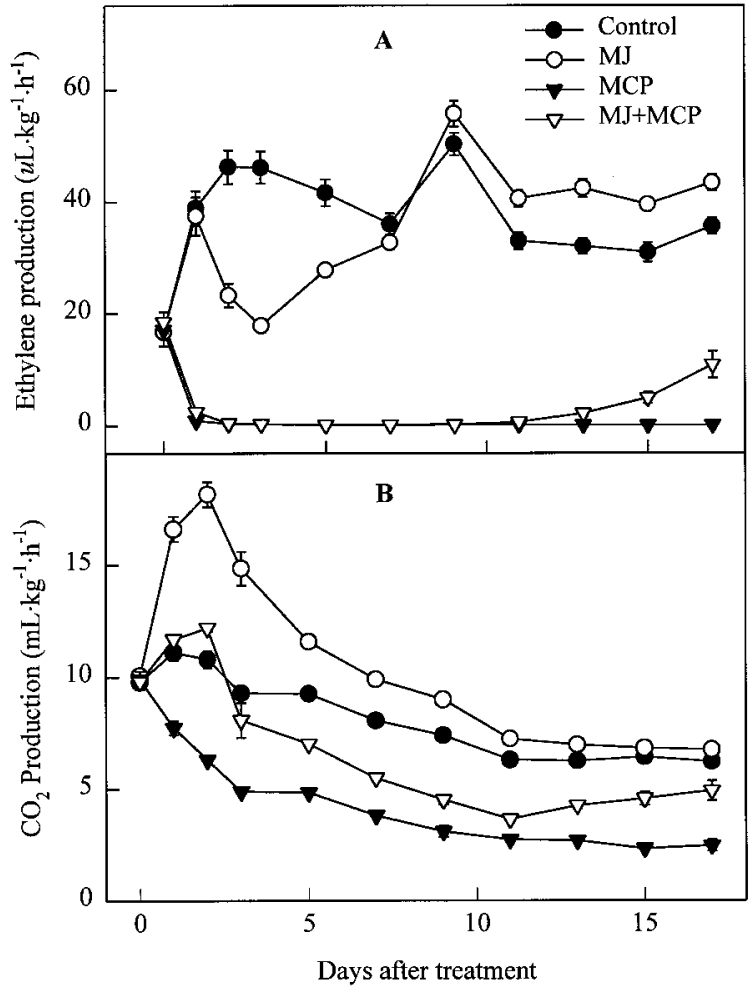

Fig. 1. Interactive effects of methyl jasmonate (MJ) and 1-methylcyclopropene (MCP) on (A) ethylene production and $(\mathbf{B}) \mathrm{CO}_{2}$ production of 'Fuji' apples. Fruit were treated with water (control), $2 \mathrm{mmol} \cdot \mathrm{L}^{-1}$ $\mathrm{MJ}, 0.45 \mathrm{mmol} \cdot \mathrm{m}^{-3} \mathrm{MCP}$ or a combination of $2 \mathrm{mmol} \cdot \mathrm{L}^{-1} \mathrm{MJ}$ and $0.45 \mathrm{mmol} \cdot \mathrm{m}^{-3} \mathrm{MCP}(\mathrm{MJ}+\mathrm{MCP})$. Vertical bars represent SE of mean.

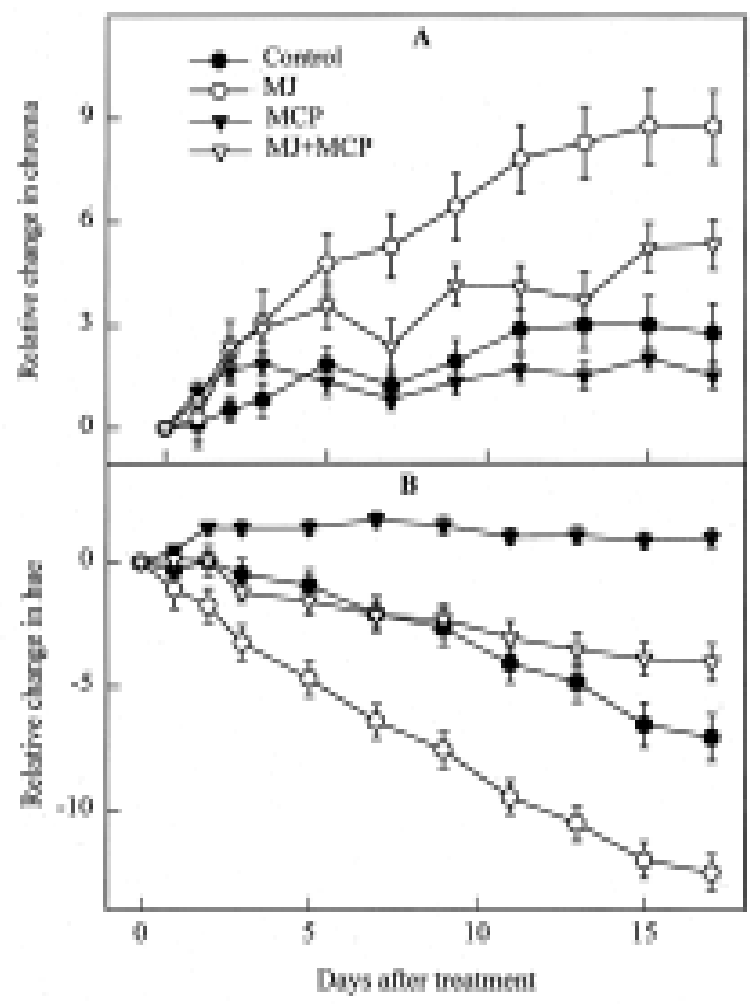

Fig. 2. Interactive effects of methyl jasmonate (MJ) and 1-methylcyclopropene (MCP) on (A) chroma and (B) hue of 'Fuji' apples. Fruit were treated with water (control), $2 \mathrm{mmol} \cdot \mathrm{L}^{-1} \mathrm{MJ}, 0.45 \mathrm{mmol} \cdot \mathrm{m}^{-3} \mathrm{MCP}$ and combination of $2 \mathrm{mmol} \cdot \mathrm{L}^{-1} \mathrm{MJ}$ and $0.45 \mathrm{mmol} \cdot \mathrm{m}^{-3} \mathrm{MCP}(\mathrm{MJ}+\mathrm{MCP})$. Initial chroma and hue values were 39.29 and 106.27 , respectively. Vertical bars represent SE of mean. moted color change even when ethylene production was inhibited by MCP, and the magnitude of the color change was not affected by MCP (Fig. 2). This suggests that MJ promoted color change independently of ethylene action. Emery and Reid (1996) reported that MJ promoted chlorophyll degradation in the absence of ethylene action. Abeles et al. (1989) observed that MJ was as effective as ethylene in inducing chlorophyll degradation in excised cucumber (Cucumis sativus L.) cotyledons. Hung and Kao (1996), however, observed that silver thiosulfate, an inhibitor of ethylene action (Veen, 1985), inhibited MJpromoted chlorophyll degradation in detached maize (Zea mays L.) leaves, and concluded that MJ-promoted chlorophyll degradation is mediated through an increase in ethylene sensitivity. Considering the evidence for ethylene promotion of chlorophyll degradation (Abeles et al., 1992), jasmonates may modulate color changes in two ways: 1) by promoting ethylene biosynthesis, ethylene in turn promoting color change and 2) independently of ethylene action as evidenced by color changes after treatment with MCP followed by MJ. The color change (yellowing) during apple fruit ripening is associated with chlorophyll degradation, carotenoid synthesis, and metabolism of other pigments. Both ethylene and jasmonate can promote chlorophyll degradation and $\beta$ carotene synthesis (Perez et al., 1993; Saniewski and Czapski, 1983), but whether MJ and ethylene mediate pigment metabolism in similar ways is not known.

In summary, MCP blocked ethylene production, and inhibited respiration and color changes in apple fruit, whereas MJ promoted color change and enhanced respiration even in fruit that produced no detectable ethylene. Our results indicate that $\mathrm{MJ}$ can act independently of ethylene action on color change and respiration of apple fruit, and may promote color change in two ways, one ethylene-dependent and the other ethylene-independent.

\section{Literature Cited}

Abeles, F.B., W.L. Hershberger, and L.J. Dunn. 1989. Hormonal regulation and intracellular localization of a 33-kD cationic peroxidase in excised cucumber cotyledons. Plant Physiol. 89:664-668.

Abeles, F.B., P.W. Morgan, and M.E. Saltveit. 1992. Ethylene in plant biology. Academic Press, San Diego.

Blankenship, S.M. and E.C. Sisler. 1993. Response of apples to diazocyclopentadiene inhibition of ethylene binding. Postharvest Biol. Technol. 3:95-101.

Burg, S.P. and E.A. Burg. 1962. The role of ethylene in fruit ripening. Plant Physiol. 37:179-189.

Creelman R.A. and J.E. Mullet. 1997. Biosynthesis and action of jasmonates in plants. Annu. Rev. Plant Physiol. Plant Mol. Biol. 48:355-381.

Emery, R.J.N. and D.M. Reid. 1996. Methyl jasmonate effects on ethylene synthesis and organ-specific senescence in Helianthus anпииs seedlings. Plant Growth Regulat. 18:213-222.

Fan, X., J.P. Mattheis, and D. Buchanan. 1998a. Continuous requirement of ethylene for apple fruit volatile synthesis. J. Agr. Food Chem. 48:1959-1963.

Fan, X., J.P. Mattheis, and J.K. Fellman. 1998b. A 
role for jasmonate in climacteric fruit ripening. Planta 204:444-449.

Fan, X., J.P. Mattheis, and J.K. Fellman. 1998c. Responses of apples to postharvest jasmonate treatments. J. Amer. Sci. Hort. Sci. 123:421-425.

Fan, X., J.P. Mattheis, J.K. Fellman, and M.E. Patterson. 1997. Effect of methyl jasmonate on ethylene and volatile production by Summerred apples depends on fruit developmental stage. J. Agr. Food Chem. 45:208-211.

Hung, K.T. and C.H. Kao. 1996. Promotive effect of jasmonates on the senescence of detached maize leaves. Plant Growth Regulat. 19:77-83.

McGuire, R.G. 1992. Reporting of objective color measurements. HortScience 27:1254-1255.

Perez, A.G., C. Sanz, D.G. Richardson, and J.M. Olias. 1993. Methyl jasmonate vapor promotes $\beta$-carotene synthesis and chlorophyll degrada- tion in Golden Delicious apple peel. J. Plant Growth Regulat. 12:163-167.

Saniewski, M. and J. Czapski. 1983. The effect of methyl jasmonate on lycopene and $\beta$-carotene accumulation in ripening red tomatoes. Experientia 39:1373-1374.

Saniewski, M., J. Czapski, J. Nowacki, and E. Lange. 1987. The effect of methyl jasmonate on ethylene and 1-aminocyclopropane-1-carboxylic acid production in apple fruits. Biol. Plant 29:199203.

Sembdner, G. and B. Parthier. 1993. The biochemistry and the physiological and molecular actions of jasmonates. Annu. Rev. Plant Physiol. Plant Mol. Biol. 44:569-589.

Serek, M., E.C. Sisler, and M.S. Reid. 1994. A volatile ethylene inhibitor improves the postharvest life of potted roses. J. Amer. Soc. Hort.
Sci. 119:572-577.

Sisler, E.C. and M. Serek. 1997. Inhibitors of ethylene responses in plants at the receptor level: Recent developments. Physiol. Plant 100:577582.

Sisler, E.C., M. Serek, and E. Dupille. 1996. Comparison of cyclopropene, 1-methylcyclopropene, and 3,3-dimethylcyclopropene as ethylene antagonists in plants. Plant Growth Regulat. 18:169-174.

Ueda, J. and J. Kato. 1980. Isolation and identification of a senescence-promoting substance from wormwood (Artemisia absinthium L.). Plant Physiol. 66:246-249.

Veen, H. 1985. Antagonistic effect of silver thiosulfate or 2,5-norbornadiene on 1-amino-cyclopropane-1-carboxylic acid-stimulated growth of pistils in carnation buds. Physiol. Plant. 65:2-8 . 